\title{
Does Corporate Culture Affects Performance of Insurance Corporate
}

\author{
Fu Jie \\ School of Economy and Management \\ BeiHang University, Beijing, China, 100041
}

\begin{abstract}
Corporate culture is the base factor for living and healthy development, and excellent corporate culture plays an important role in raising its competitive capacity. The purpose of this article is two fold: first, this paper tries to demonstrate the corporate culture base on the $6 \mathrm{~S}$ model which proposed by American Scholar McKinsey. Second, I try to propose and test how corporate culture affects performance under the background of China's strongly developing insurance and with the pushing forward of governments' supporting policy by a cross-sectional logistic regression model. The results show that corporate culture has a significant relationship with performance, and the insurance corporate with high level corporate culture has better performance than low level corporate culture.
\end{abstract}

Keywords: Corporate Culture; Insurance Corporate; Organizational Performance; 6S Model

\section{Introduction}

Corporate culture is developed and formed with the whole staffs' long-term business and development, including the highest goals, value standard and fundamental beliefs abided by the staff (Zhou Hai(2008) ${ }^{[1]}$ ). George A. Marcoulides, Ronald H. Heck(1993) $)^{[2]}$ use LISREL modeling methodology to estimate and test the relationship between organizational culture and performance, the results show that the comparison of visible aspects of culture across and within organizations can provide useful information for guiding the directions of organizations, and it may eventually be possible to explain why some organizations are not performing at desired levels of productivity.

Dr. Gao-Liang Wang(2012) $)^{[3]}$ focuses on path coefficient between "implicit/ latent variables" of structural model with Bayesian Estimation, and the results show that organizational culture has a positive, significant and direct influence on organizational performance, and organizational culture has a significantly positive influence on IC, which in turn affects the organizational performance in a significant and positive manner. Jennifer A. Chatman (2013) ${ }^{[4]}$ suggest that the relationship between organizational culture and performance can be reconciled by recognizing from three components: the content of norms, how intensely organizational members hold those norms, and how widely members agree about the norms within the organization. Nor Aini Yusof and Nazirah Zainul Abidin $(2011)^{[5]}$ conducted among all housing developers registered with the Bursa Malaysia, and the results revealed that assertiveness culture had highly significant relationships with organizational innovativeness.

A number of studies the corporate culture of insurance corporate. ZhuoZhi $(2009)^{[6]}$ shows that insurance industry 
corporate culture is the combination of material and spiritual achievements created by insurance agencies and insurance practitioners, which is the backbone or manner or engine of development of the corporate. Zhou Hai $(2008)^{[7]}$, Li Shaofang $(2008)^{[8]}$ try to explain the construction of corporate culture, and the results shows that improving insurance culture construction is the raw power of consolidating the staff's willing and boosting their morale, but also an important means to demonstrate the industry's image and enhance the status of the industry. Other studies such as Wang Min, Wen Guofeng(2011) ${ }^{[9]}$, Li Zhi Qiang; Zhou $\operatorname{Jiong}(2008)^{[10]}$, Zhu Jinyuan $(2012)^{[11]}$ explain the relationship between corporate culture and performance in different ways.

In this paper, a cross-sectional logistic regression model and $6 \mathrm{~S}$ model to study how the organizational culture affects organizational performance of insurance corporate. The remainder of this paper is organized as follows. Section 2 is the Model. The data is discussed in section 3. Section 4 describes the results of analysis, and section 5 is the conclusions.

\section{The Method and Sample}

\subsection{Character of Corporate Culture}

This Paper uses 6S model to character corporate culture of insurance corporate, and aims at the enterprise value increment by the means of collaborative innovation of various management elements and culture elements. The $6 \mathrm{~S}$ model of corporation culture indicates the characteristic of insurance management system, and bases on the effective strategy, structure, system, style, staff and skill. Fig 1 is the structure of the insurance corporate culture.

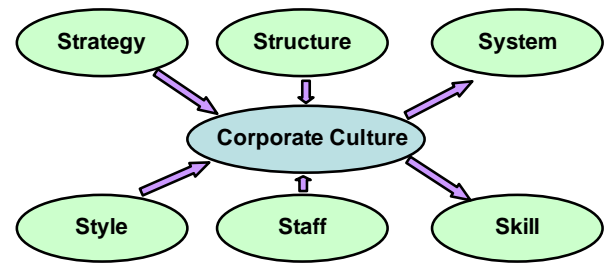

Fig. 1: The Structure of corporate Culture

- Strategy

The key point to maximize the insurance corporate value and its sustainable development is to set a reasonable and long-term strategy. One company can depend on opportunities in 3-year development, but can only depend on strategy to develop a decade. Especially to an insurance enterprise, it can make considerable profits in a short period for seizing a very good opportunity. Therefore the insurance corporate construction must pay much attention to the enterprise strategy.

- Structure

Reasonable organization structure is beneficial to the business operation and guarantees the successful execution of enterprise development strategy. Highquality service usually relies on the efficiently operation among various organizations, which can greatly shorten the time of claim and its settlement, improve the applicants' satisfaction degree and attract more and more customers.

- System

Corporate culture is a kind of invisible management system. System is the visible external constraints, while culture is an invisible inner consciousness, so culture construction must depend on the construction of management system. Insurance industry also needs a scientific and reasonable system to guarantee benign operation and development.

- Style

The style of insurance industry is mainly focus on staff's service conscious, 
service consciousness is a person's understanding of the service and the conscious behavior showed after understanding the service. Insurance belongs to service industry, the work is done by all the employees, and the strength of the service consciousness of employees has a direct impact on applicant understanding toward insurance and their satisfaction degree.

- Staff

Human resource is one of the most important resources in enterprise; the development of an enterprise is inseparable from person elements, the competitiveness of the enterprise is actually the externalization of personal competitiveness. So, how to stimulate the staffs' strength to better perform is a question the enterprise must think about.

- Skill

Technology determines the degree of enterprise specialization. Insurance is an industry needing numerous of comprehensive skills, the field involved is very wide, needing marketing skills in business and marketing is usually an art, especially insurance marketing needs to deal with all kinds of potential applicants, so it needs a stronger management and other knowledge.

This paper use the method of specialist investigates to analysis quantifiably the corporate culture of insurance corporate.

\subsection{The model}

A cross-sectional logistic regression is used to examine the relationship between corporate culture and performance, and the model can be described by:

$R O E_{i}=c+\beta_{1} C U L_{i}+\beta_{2} A L R_{i}+\beta_{3} M V_{i}+\beta_{4} E C_{i}+\varepsilon$

Where $R O E_{i}$ is return on equity of firm i, which indicates the performance of insurance corporate. $C U L_{i}$ is the indicator of corporate culture of firm i, which including strategy, structure, system, style, staff and skill, and the numerical value limits 0 to 1 . $A L R_{i}$ is asset-liability ratio of firm i. $M V_{i}$ is the incremental speed of book value of firm $i$ in sample year. $E C_{i}$ is the character of firm i. $\beta_{1}, \beta_{2}, \beta_{3}, \beta_{4}$ are coefficient of regression.

\subsection{The Sample}

The sample of insurance firms is obtained from questionnaire survey. I provide 250 questionnaires, and got 248 effective questionnaires of 52 insurance firms. Parts of data come from wind database.

\section{The Results}

\subsection{Statistic Description of Feature Indexes}

Table 1 provides the average of feature index of sample. I divide the sample into two groups according the level of corporate culture, one is high level group, the other is low level group.

Table 1: The average of feature index

\begin{tabular}{|l|l|l|l|}
\hline & $\begin{array}{l}\text { Total } \\
\text { samples }\end{array}$ & $\begin{array}{l}\text { High } \\
\text { level }\end{array}$ & $\begin{array}{l}\text { Low } \\
\text { level }\end{array}$ \\
\hline$R O E$ & 0.1346 & 0.1857 & 0.0923 \\
\hline$C U L$ & 0.3681 & 0.5892 & 0.2252 \\
\hline$A L R$ & 0.4516 & 0.4617 & 0.4219 \\
\hline$M V$ & 0.1561 & 0.1832 & 0.0983 \\
\hline
\end{tabular}

The results show that the mean CUL of total sample is 0.3681 , while the high level corporate culture and low level corporate culture are $0.5892,0.2252$. The performance of two groups has disparity. ROE of high level corporate culture group is 0.1857 , while ROE of low level corporate culture group is 0.0923 .

\subsection{The Result of Regression}

Table 2 contains the result of the crosssectional logistic regression model, Model 1 is the complete while model 2 and model 3 are variations of model 1, which estimated by eliminating variables that are correlated with asset-liability ratio and the character of firm. 
Table 2: The Result of Regression

\begin{tabular}{|l|l|l|l|}
\hline$R O E$ & $(1)$ & $(2)$ & $(3)$ \\
\hline$C$ & 0.518 & 0.319 & 0.484 \\
\hline \multirow{2}{*}{$C U L$} & $\begin{array}{l}0.131^{*} \\
(1.756)\end{array}$ & $\begin{array}{l}0.118 \\
(1.362)\end{array}$ & $\begin{array}{l}0.156^{* *} \\
(2.165)\end{array}$ \\
\hline \multirow{2}{*}{$A L R$} & $\begin{array}{l}-0.162 \\
(0.819)\end{array}$ & & $\begin{array}{l}-0.131 \\
(-1.817)\end{array}$ \\
\hline \multirow{2}{*}{$M V$} & $\begin{array}{l}0.281 \\
(0.128)\end{array}$ & $\begin{array}{l}0.188^{*} \\
(1.781)\end{array}$ & $\begin{array}{l}0.113^{*} \\
(1.215)\end{array}$ \\
\hline \multirow{2}{*}{$E C$} & $\begin{array}{l}0.182^{*} \\
(1.716)\end{array}$ & $\begin{array}{l}0.113 \\
(0.981)\end{array}$ & \\
\hline
\end{tabular}

*Represent significance at the $10 \%$ level, ** Represent significance at the 5\% level.

Results from model 1and model 2 shows that CUL is significant predictors of ROE of insurance corporate. Results from model 2 and model 3 shows that $\mathrm{MV}$ is significant predictors of performance of insurance corporate. It means that the corporate can improve its performance by paying more attention to the development of corporate culture.

\section{Conclusion}

In this paper, I try to explain how corporate culture affects performance of insurance corporate by a cross-sectional logistic regression model. The results indicate that the level of culture has significant positive relevance with performance of insurance corporate, and it is helpful to pay attention to the strategy, structure, system, style, staff and skill in culture construction.

\section{References}

[1] Zhou Hai, "Strengthen insurance corporate culture construction to build a harmonious enterprise", Journal of insurance research, pp321$345,2008$.

[2] George A. Marcoulides \& Ronald H. Heck, "Organizational Culture and Performance: Proposing and Testing a Model", Organization Science, pp209-225, 1993.
[3] Dr. Gao-Liang Wang, "A Study of How the Organizational Culture of International Tourist Hotels Affects Organizational Performance: Using Intellectual Capital as the Mediating Variable", The Journal of Global Business Management, pp:189-201, 2012.

[4] Jennifer A. Chatman, "Parsing Organizational Culture: The Joint Influence of Culture Content and Strength on Performance in High Technology Firms", Working Paper, 2012.

[5] Nor Aini Yusof and Nazirah Zainul Abidin, "Does Organizational Culture Influence the Innovativeness of Public-Listed Housing Developers?", American Journal of Applied Sciences, pp724-735, 2011.

[6] ZhuoZhi, "Several basic problems of China's insurance cultures", Journal of insurance research, pp: 132-153, 2009.

[7] Zhou Hai, "Strengthen insurance corporate culture construction to build a harmonious enterprise", Journal of insurance research, pp321345,2008.

[8] Li Shaofang, "Theory of the cultural development and construction of the insurance industry", Journal of insurance research, pp: 289-311,2008.

[9] Wang Min, Wen Guofeng, "Application of 7S Model on Property Management Corporate Culture Construction”, 2011 International Conference on Engineering and Business Management, Scientific Research, 2011.

[10] Li Zhi Qiang and Zhou Jiong, "The path of insurance corporate culture construction research", Journal of insurance research, pp:102-118, 2008.

[11] Zhu Jinyuan, "Promote cultural construction of the insurance", China financial, pp34-39, 2012 